\title{
SELF-DIRECTION FOR THE ADULT LEARNER: EFFECT OF PROGRAM DESIGN ON LEARNER MOTIVATION AND TRAINING UTILITY
}

\author{
Nicole Cannonier, Savannah State University, U.S.A. \\ Reid Bates, Louisiana State University, U.S.A.
}

dx.doi.org/10.18374/IJBR-20-1.6

\begin{abstract}
PurposeAndragogy and self-directed learning (SDL) have long been touted as pillars of adult learning theory, but much of the existing SDL research has been predicated on adult learner assumptions that have gone largely untested. This research developed a model based on adult learning and training literature to assess the outcomes of adults' preference for SDL. The model was tested on a sample of 277 adults participating in job-related training through a continuing education program at a university in the southern United States. It was hypothesized that self-directed learning preference (SDLP) would positively influence motivation to improve work through training (MTIWL) and training utility (TU) based on the expectancy theory premise that more learner control would be beneficial for learner motivation and perceived training utility. Additionally, the extent to which andragogical principles were present in course designs was proposed to moderate the relationship between SDLP and MTIWL, and SDLP and TU. Person-environment fit theory suggested that persons would be more motivated to use their training at work and perceive it as more useful if there were congruence between their SDLP and the andragogical design (AD) of a course (i.e., low SDLP and low AD versus high SDLP and high $A D$ ). The study model was tested using structural equation modeling and partially supported the hypothesized relationships. SDLP was shown to be a significant predictor of MTIWL but was not shown to be a predictor of TU. AD exhibited weak to moderate main effects on TU and MTIWL and significantly moderated the relationship between SDLP and TU but not SDLP and MTIWL. Implications of the study and avenues for future research are discussed.
\end{abstract}

Keywords: Self-Directed Learning; Andragogy; Training Utility; Motivation to Improve Work Through Learning; Human Resource Development 